\title{
Factors that Influence the Dissemination and Implementation of a School Health Policy
}

Helen I. Wankasi

https://orcid.org/0000-8403-5555

North-West University, South Africa

hidubamo@gmail.com

\section{Mahlasela A. Rakhudu}

https://orcid.org/0000-0003-0573-0734

North-West University, South Africa

Hunadi.Rakhudu@nwu.ac.za

\author{
Leepile A. Sehularo \\ https://orcid.org/0000-0003-4286-6761 \\ North-West University, South Africa \\ Leepile.Sehularo@nwu.ac.za
}

\section{Abstract}

The policy on school health is ineffectively disseminated and poorly implemented in many contexts. The purpose of this study was to explore and describe the factors that influence the dissemination and implementation of a policy on school health in Bayelsa state in southern Nigeria. A qualitative approach (using an exploratory, descriptive and contextual research design) was used to achieve the aim of the study. Non-probability purposive sampling was used to select 24 participants for the study. Semi-structured individual interviews and an Olympus VN-7800 audio tape were used to collect data. The data were analysed concurrently using line-by-line the six inductive steps of a thematic analysis as well as Atlas ti version 8.0 to ensure consistency of the findings. The results show that bureaucracy, ineffective monitoring and evaluation, insufficient financial support, political interference, lack of equity of service delivery, poor working conditions, ineffective communication, and lack of knowledge and awareness are perceived as barriers to such a policy. Accessibility to policy documents, collaborative partnership, existing school health programmes, and competent and willing personnel are perceived as positive factors for the dissemination and implementation of such a policy. This study would contribute towards the improvement of school health and educational practices if the findings and recommendations are implemented appropriately.

\section{UNISA $\cong$}


Keywords: dissemination; factors; implementation; southern Nigeria; school health policy

\section{Introduction and Background}

The Council on School Health in Europe defines school health as "the incorporation of programmes and relevant stakeholders to promote an individual child's behaviour to attain optimal health, ensure security, steady development and increase learning habit while at school" (Bradbury and Roberts-Holmes 2016, 32). Developed countries and certain regions have progressed in the school health programmes of the World Health Organization (WHO) and comply with the minimum standards for their respective regions, such as Europe, America, South East Asia and the Western Pacific region (Rasesemola, Matshoge, and Ramukumba 2019,2). Africa, Ghana, Botswana and Nigeria have had more than a decade of complete school health programmes and policies running. However, there is still a serious concern of non-compliance with the minimum standards recommended by the WHO. This information provides the rationale for the current study.

Adebayo and Onadeko $(2015,56)$ mentioned that the school health policy in Nigeria includes school feeding services and home relationships. If a school health policy is disseminated and its services are effectively implemented, the promotion of activities on school health would be uninterrupted (WHO 2017,9). Additionally, the South African Integrated School Health Policy (National Departments of Health and Basic Education 2012,6) indicates that school health policies are likely to afford a safety net for the schoolchildren who do not access any preventive health services during their preschool years, and are able to identify preventable health problems that may constitute barriers to teaching and learning. Ultimately, the optimal health and academic performance of schoolchildren will be achieved as stated in the definition of school health above. This justifies why the researchers decided to explore and describe the factors that influence the dissemination and implementation of a school health policy in Bayelsa state, southern Nigeria, based on the decision makers' views.

The literature reveals several factors that influence the implementation of a school health policy (Macnab, Gagnon, and Stewart 2014, 170; Saito et al. 2014, 843). For instance, in the Mpumalanga and Gauteng provinces of South Africa, a qualitative study was conducted to describe barriers to successful implementation of school health services with key role players. The study revealed that the lack of management and government interest, among others, affected effective implementation (Mohlabi, Van Aswegen, and Mokoena 2010, 252). Hildebrand, Betts, and Gates $(2019,498)$ argued that literature is limited on parents' involvement in the implementation of school policies. These factors negate the purpose of the Sustainable Development Goal of sustaining the promotion of school health practices. 
A quantitative study by Rasesemola, Matshoge, and Ramukumba $(2019,1)$ indicated that the implementation of a school health policy needs a strong intersectoral collaboration on the part of key role players such as the Department of Basic Education, the Department of Health and also the Department of Social Development. These departments and educational structures such as teachers' unions, civil society, learner organisations, academic institutions, school governing bodies, and development partner organisations are also expected to make a contribution to the development of sustainable and comprehensive school health programmes.

In Nigeria, Obembe, Osungbade, and Ademokun $(2016,217)$ conducted a quantitative study to ascertain the knowledge and awareness of a national school health policy among high school teachers in South-West Nigeria using a descriptive cross-sectional pre- and post-test quantitative study. The results revealed that one-third of the teachers were aware of school health policy; however, less than one quarter of this number had seen the policy. This is an indication that there is a problem with regard to its dissemination and it is likely that this could affect the implementation of the policy in Nigeria. As a result, there is a need for deliberate action to be taken in order to explore and describe decision makers' perspectives of the factors that influence the dissemination and implementation of a school health policy in Bayelsa state, southern Nigeria. Based on the above discussion, this study could enable the researcher to better understand issues at stake and take proactive steps, considering the fact that the description of early valid factors promotes "progressive course" to show a clear pathway towards the improvement of the delivery of school health services (Koegel et al. 2014, 53). The findings of this study could be used to facilitate the effective dissemination and implementation of school health policy in public schools in Bayelsa state, southern Nigeria.

\section{Problem Statement}

Literature on implementation of a school health policy is available (Brener, Wechsler, and Kann 2014,688). However, the policy on school health is ineffectively disseminated and poorly implemented in many contexts including Bayelsa state, southern Nigeria. This leads to poor health services in public schools. For instance, some of the school environments are unattractive, unconducive and deplorable. This results in schoolchildren to be emotionally, physically and socially compromised, leading to hooliganism, sickness related to absenteeism and poor academic performance as well as health and educational inequalities (Ofovwe and Ofili 2010, 1572). In spite of the above challenges, no steps have been taken to ensure the proper dissemination and implementation of a school health policy in Bayelsa state, southern Nigeria. If the factors responsible for this situation are not unravelled, school health services and stakeholders could face more hurdles, since they will be unable to seek appropriate assistance on a continuous basis. These challenges prompted the researchers to embark on this study with the aim of exploring and describing the factors that influence the 
dissemination and implementation of a school health policy in Bayelsa state, southern Nigeria.

\section{Purpose of the Study}

The purpose of this study was to explore and describe the factors that influence the dissemination and implementation of a school health policy in Bayelsa state, southern Nigeria.

\section{Research Design}

A qualitative, exploratory, descriptive and contextual research design was used to explore and describe the factors that influence the dissemination and implementation of a school health policy in Bayelsa state, southern Nigeria. Brink, Van der Walt, and Van Rensburg $(2012,120)$ state that qualitative research design is relevant for exploring, describing and providing an in-depth understanding of a phenomenon, when little is known about the phenomenon, or when the nature, context and boundaries of a phenomenon are poorly understood and defined.

\section{Population and Sampling}

The target population for the study involved directors (healthcare professionals), professional teachers and UNICEF representatives. A non-probability purposive sampling technique was used to recruit eligible participants (members of different professional bodies in Bayelsa state, southern Nigeria). The participants were purposively selected owing to their senior positions and direct involvement in the promotion of school health. This shows that the participants were selected because they were knowledgeable and experienced in the development and implementation of a school health policy in Bayelsa state, southern Nigeria. Students were excluded from participating in the study because they are not responsible for the implementation of the school health policy. The sample size was reached after interviewing 24 participants.

\section{Data Collection}

Semi-structured individual interviews and field notes were used to collect data from 1 to 21 November 2018. An Olympus VN-7800 was used to record the voices of the participants. All interviews were conducted in the private offices of the participants from Ministries A, B and C from Bayelsa state, southern Nigeria. For the sake of uniformity and consistency, all participants were asked the same question as follows: "What are the factors that influence the dissemination and implementation of a school health policy in southern Nigeria?" Each interview session lasted between 22 and 45 minutes, which, to an extent, depended on the willingness of the individual 
participants and the time allocated by the participants for the interview taking into consideration their daily schedule.

\section{Data Analysis}

Data collection and analysis occurred concurrently in this study. Tesch's method of thematic analysis (Creswell and Plano Clark 2017, 44) and the Atlas ti version 8.0 were used to analyse the data. The steps included transcribing the interviews verbatim to make sense of the information, identifying categories that emerged from the data, clustering categories together, creating a coding scheme, utilising the themes and categories identified, and selecting quotes that best illustrated the meaning of each category.

\section{Ethical Considerations}

The study was approved by the Health Research Ethics Committee of the School of Nursing Science, North-West University (NWU) (Reference number NWU-00633-18A9). Permission was requested and obtained from gatekeepers in Bayelsa state, southern Nigeria. Informed consent was obtained from all participants before their voluntary participation in the study. The researcher maintained the participants' right to privacy, anonymity and confidentiality, fair treatment and also the right to protection from discomfort and harm.

\section{Trustworthiness}

Trustworthiness was maintained by following the principles of Lincoln and Guba (Brink, Van der Wath, and Van Rensburg 2012, 171). The researcher observed the principles of credibility, dependability, confirmability and transferability. To ensure credibility, the data were obtained from the relevant stakeholders and context and also the length of time (22-45 minutes) allocated for the interviews. To guarantee a high degree of dependability, the data collection and analysis were done by the first author, and two independent coders recoded the findings for consistency of data. The study was done under the supervision of two qualitative researchers. To ensure confirmability or an audit trail, the transcripts were handed over to supervisors and co-coders, an indication that the data were the true reflection of the views of the participants and not the researchers' perceptions or biases. Member-checking was also done to ensure that the ideas of the participants were not misrepresented. Lastly, the findings were compared with those of the co-coders. Transferability was ensured by providing evidence that the three institutions selected for the study had the same categories of professionals and that the schools were involved in the promotion of activities related to school health. 


\section{Findings}

Two themes emerged from the study, namely perceived barriers, and perceived positive factors. The results are presented and discussed below.

\section{Demographic Characteristics of Participants}

Individual interviews were conducted with 24 participants. All interviews were conducted in the offices of the participants. Table 1 shows the demographic characteristics of the participants.

Table 1: Interviews conducted with the participants according to the characteristics (Ministries A, B and C)

\begin{tabular}{|c|c|c|c|c|c|c|}
\hline Participant & Ministry & Gender & Age & Qualification & $\begin{array}{l}\text { Years in } \\
\text { service }\end{array}$ & Position \\
\hline $\mathrm{P} 1$ & $\mathrm{~A}$ & Male & 56 & MSc & 22 & $\begin{array}{l}\text { Director (Desk } \\
\text { Officer) }\end{array}$ \\
\hline $\mathrm{P} 2$ & $\mathrm{~A}$ & Male & 48 & BEd & 20 & Director \\
\hline P3 & $\mathrm{A}$ & Male & 46 & PGD (Ed) & 17 & Director \\
\hline P4 & $\mathrm{A}$ & Male & 49 & $\mathrm{BSc}$ & 24 & Director \\
\hline P5 & $\mathrm{A}$ & Female & 59 & $\mathrm{PhD}$ & 26 & $\begin{array}{l}\text { Director } \\
\text { (UNICEF } \\
\text { Rep) }\end{array}$ \\
\hline P6 & A & Male & 55 & BSc & 25 & Director \\
\hline $\mathrm{P} 7$ & A & Male & 56 & MSc & 22 & Director \\
\hline $\mathrm{P} 8$ & $\mathrm{~A}$ & Female & 48 & $\mathrm{BEd}$ & 20 & Director \\
\hline P9 & A & Male & 55 & BEd & 28 & Director \\
\hline $\mathrm{P} 10$ & $\mathrm{~A}$ & Male & 58 & Med & 27 & Director \\
\hline P11 & $\mathrm{A}$ & Male & 56 & PGD (Ed) & 22 & Director \\
\hline $\mathrm{P} 12$ & $\mathrm{~A}$ & Male & 46 & PGD (Ed) & 20 & Director \\
\hline P13 & $\mathrm{A}$ & Male & 50 & BEd & 20 & Director \\
\hline P14 & B & Male & 51 & BEd & 21 & Director \\
\hline $\mathrm{P} 15$ & B & Male & 51 & $\mathrm{BSc}$ & 30 & $\begin{array}{l}\text { Director (Desk } \\
\text { Officer) }\end{array}$ \\
\hline P16 & B & Female & 54 & MSc & 20 & $\begin{array}{l}\text { Director } \\
\text { (UNICEF } \\
\text { Rep) }\end{array}$ \\
\hline P17 & $\mathrm{C}$ & Male & 52 & MBBS & 23 & Director \\
\hline P18 & $\mathrm{C}$ & Male & 49 & MPH & 19 & Director \\
\hline P19 & $\mathrm{C}$ & Male & 48 & MBBS & 14 & Director \\
\hline $\mathrm{P} 20$ & $\mathrm{C}$ & Female & 47 & MSc & 19 & Director \\
\hline P21 & $\mathrm{C}$ & Female & 45 & MSc & 20 & Director \\
\hline P22 & $\mathrm{C}$ & Female & 49 & MPH & 20 & Director \\
\hline P23 & $\mathrm{C}$ & Male & 58 & $\mathrm{PhD}$ & 28 & Director \\
\hline P24 & $\mathrm{C}$ & Female & 53 & MPH & 25 & Director \\
\hline
\end{tabular}


The 24 individual interview sessions produced two themes, namely perceived barriers and perceived positive factors to the dissemination and implementation of a school health policy in southern Nigeria. The themes and sub-themes are presented in Table 2.

Table 2: Factors that influence the dissemination and implementation of a school health policy in Bayelsa state, southern Nigeria

\begin{tabular}{|l|l|}
\hline Themes & Sub-themes \\
\hline Perceived & Bureaucracy \\
& Ineffective monitoring and evaluation \\
& Insufficient financial support \\
& Political interference \\
& Lack of equity of service delivery \\
& Poor working conditions \\
& Ineffective communication \\
& Lack of knowledge and awareness \\
\hline $\begin{array}{l}\text { Perceived } \\
\text { positive factors }\end{array}$ & $\begin{array}{l}\text { Accessibility to policy documents } \\
\text { Collaborative partnership } \\
\end{array}$ \\
& Existing school health programmes \\
& Competent and willing personnel \\
\hline
\end{tabular}

\section{Theme 1: Perceived Barriers}

Eight sub-themes emerged from this theme, namely bureaucracy, ineffective monitoring and evaluation, insufficient financial support, political interference, lack of equity of service delivery, poor working conditions, ineffective communication and a lack of knowledge and awareness. These sub-themes are discussed below.

\section{Bureaucracy}

Bureaucracy is a system of government in which most of the important decisions are administered by departments and officers. Owing to its hierarchical order, effective decision-making is leisurely. Some participants maintained that too much bureaucracy was the cause of the ineffectiveness in the delivery of school health services. The participants mentioned that bureaucratic processes cause the dissemination and implementation of school health policies to be slow. One participant suggested that government bureaucratic processes should be reconsidered to ensure proper dissemination and implementation of school health policies. In other words, a slow bureaucratic process was a barrier to the dissemination and implementation of a school health policy in Bayelsa state, southern Nigeria, as captured in the excerpts below:

You know government bureaucratic processes are slow, especially when it comes to educational policies. (P10 Male) 
I really blame our government on the issue of implantation of school health policies. (P5 Female)

Our major challenge here in the state is that the school health policy is not yet legitimised by our legislators. (P21 Female)

\section{Ineffective Monitoring and Evaluation}

Ineffective monitoring and evaluation was the second sub-theme identified under the perceived barriers for the dissemination and implementation of a school health policy in Bayelsa state, southern Nigeria. The participants indicated that owing to the ineffective monitoring and evaluation of the dissemination and implementation of the school health policy processes, there is a lack of enforcement, poor compliance and a lack of succession planning. This shows that government still has a lot to do in order to enjoy the benefits of school health policies. This finding is captured in the following excerpts:

Then improper monitoring, evaluation and supervision are also affecting all programmes or policies we carry out in our schools. We have no facilities to effectively monitor programmes in our secondary schools. (P24 Female)

There is no mechanism for evaluating the effectiveness to ensure compliance and support of those the policy intended to benefit. (P3 Male)

We also need to appropriate reports sent to us for evaluation of school health policies. (P18 Male)

\section{Insufficient Financial Support}

The participants indicated that financial support for implementing policies in schools is insufficient. A participant mentioned that the government has not allocated substantial funds to assist the school health sector. The majority of the participants from the three ministries stressed that insufficient financial support is a barrier to the dissemination and implementation of a school health policy in southern Nigeria. The lack of funding, no budget, and, at times, no budget implementation were some of the constraints as captured in the following excerpts:

We also have a problem of poor financial support from our government and this has paralysed almost every activity related to schools. (P2 Male)

... because there is not enough funding to implement policies here, life is extremely difficult for the learners. (P13 Male)

As I said, we do not know anything about school health policy, so no budget to that effect. (P1 Male) 


\section{Political Interference}

Political interference was the fourth sub-theme to be identified in the study. The participants indicated that the incessant interference of politicians in the health affairs of schools has caused a significant setback in the dissemination and implementation of a school health policy in southern Nigeria. The aim of such interference by politicians was to empower political allies of the government without realising the consequences. Such consequences include the sidelining of stakeholders, thus not giving them the opportunity to perform their legitimate duties. Consequently, the school health policy is ineffectively disseminated and inappropriately implemented as captured in the following excerpts:

Our work is always interfered with by the politicians in this country. Schools are not given the opportunity to perform their duties without interference by politicians; these people are delaying our progress of implementing policies effectively. (P20 Female)

Teachers of this country do not have autonomy to implement policies, there is always some sort of political interference. (P12 Male)

Everything that we touch in our schools, politicians always have something to say, that's not right. (P7 Male)

\section{Lack of Equity of Service Delivery}

The lack of equity of service delivery was identified as the fifth sub-theme of the study. The participants identified the dysfunctional state of school health services due to lack of equity of service delivery. One participant added that various ministries are not treated equally in southern Nigeria. This may be due to favouritism from the senior management of the state. The participant mentioned that some states get more funds than others in southern Nigeria. The following excerpts support this finding:

Then you see this UNICEF, they are very selective. Go to the northern part of the country, they do so much for school healthcare promotion, but here in the south, situation is different. (P9 Male)

The few services carried out intermittently are not reaching all schools in the state equally partly because of favouritism. (P1 Male)

There are no good toilet facilities in some schools here in the state, people take services to where they have the interest. (P8 Female)

\section{Poor Working Conditions}

Poor working conditions are also a serious problem in Bayelsa state, southern Nigeria, as in many other countries. Poor working conditions were also highlighted as a barrier to the dissemination and implementation of a school health policy in Bayelsa state, southern Nigeria. The participants believed that government has not created the right 
atmosphere and working conditions that would favour stakeholders to effectively disseminate and implement a school health policy in southern Nigeria as revealed in the following excerpts:

Working conditions are unbearable. Even the personnel available, no promotion, no upgrading of knowledge and no regular payment, which is what holds most activities now. (P16 Female)

There is delay in payment of workers. As we speak, we are still expecting 2015 leave bonuses, this is not fair at all. (P4 Male)

The staff do not know what to do in terms of school health services as they have been deprived of it. (P1 Male)

\section{Ineffective Communication}

Ineffective communication was the second last sub-theme identified in this study. The majority of the participants highlighted the fact that a school health policy was ineffectively communicated. Thus, most stakeholders are unaware of the existence and knowledge of the content of the school health policy in the state. Furthermore, the participants believed that the stakeholders do not possess the ability and proficiency to effectively disseminate and implement a school health policy in the State as captured in the following excerpts by some of the participants:

$80 \%$ of schools are not aware of such policies and programmes. Please if you have a copy let me photocopy it. (P19 Male)

People do not want to talk, they do not want to share important information with us, that's the problem, how will we know about policies if people are not talking to us. (P23 Male)

Some people attend school meetings but when they come back, they don't share information with those who were left behind. (P11 Male)

\section{Lack of Knowledge and Awareness}

Owing to misinformation, stakeholders lack knowledge and awareness of the existence of a school health policy. The stakeholders have not seen the school health policy and are unaware of the content of such policy. Some participants maintained that stakeholders were misinformed about a school health policy, which had brought about the lack of knowledge of the content of such policy. Such knowledge could have changed the perceptions of stakeholders towards a school health policy and its associated services, and reduced the institutional intensities of discourse on a school health policy as captured by some of the participants:

The very first challenge is that the content of the said policy is not made known or available to the school heads and other staff members. (P6 Male) 
$80 \%$ of schools are not aware of such policies and programmes. Please if you have a copy let me photocopy it. (P19 Male)

The teachers out there in the schools do not know anything about school health policy ever since it was produced. (P17 Male)

\section{Theme 2: Perceived Positive Factors}

The four sub-themes that emerged from this theme were as follows: accessibility to documents; collaborative partnership; existing school health programmes; and competent and willing personnel. These sub-themes are discussed below.

\section{Accessibility to Policy Documents}

Documents are written pieces of factual information of intent and activities available in either electronic format or hard copy. The Health Education curriculum and the school health policy are available documents to disseminate and implement a school health policy. Considering the fact that documents constitute evidence-based facts and can be relied upon as evidence, the availability of such documents serve as a perceived positive factor. However, the participants maintained that such documents are not available or accessible to them. From the individual interviews, about nine participants expressed the need for the existence of a curriculum on school health, documents and school health policy and indicated that such documents and policies would enable implementers to know the purpose for which health promotion programmes are carried out in public schools within the State, as captured in the following excerpts:

Documents are available in all schools. But I do not know if the school health policy is made available and distributed to other teachers for implementation. (P14 Male)

Policy documents are only available at the senior management offices, they do not reach the people who should use them, that's our biggest problem. (P15 Male)

How do we get those policy documents because majority of us have never heard anything about them. (P15 Male)

\section{Collaborative Partnership}

The participants made a recommendation that there is a need for a collaborative partnership in order for school health policies to be implemented successfully. Collaborative partnership is alliance formation of groups having the same vision and objective. Six participants considered this sub-theme a perceived positive factor that influence the dissemination and implementation of a school health policy in Bayelsa state, southern Nigeria, as captured in the excerpts below.

People should learn to work together particularly when coming to policies related to schools, no one can do everything alone. (P15 Male) 
For us to ensure good health and safety of our schoolchildren, we need partnerships with people inside and outside of this side of the state. (P22 Female)

People from senior position to junior positions should work together, together we can achieve more especially on the issue of school health, it takes a village to raise a child. (P11 Male)

\section{Existing School Health Programmes}

There are existing school health programmes in Bayelsa state, southern Nigeria. Though some of the existing school health programmes have proved to have yielded encouraging outcomes, they have, however, been unscientific. However, a good number of the participants indicated that the existing school health programmes could enhance better decision-making to improve the promotion of school healthcare as captured in the following excerpts:

Yes, the availability of a teacher development programme that trains practising teachers is a good platform to annex the dissemination of a school health policy. (P6 Male)

For the school health programmes to survive, we need to implement a school health policy in this part of the state. (P22 Female)

We have some of the policies but the problem is that majority of them are not scientific and we don't even know the people who developed them, so we just have to make them scientific in order to achieve all our school health programmes, that's my suggestion. (P12 Male)

\section{Competent and Willing Personnel}

Competent and willing personnel was the last sub-theme of the study. Every organisation, whether private or public, needs competent and willing personnel. Competence is one's ability to administer a programme to achieve the desired goal. At least 14 participants indicated the need to use competent and willing personnel in the Ministry as perceived positive factor in furthering the course of dissemination and implementation of a school health policy as captured in the following excerpts:

I have the confidence that the teachers have the requisite qualifications and willingness to fit well in implementing the school health services because they have the competencies. (P3 Male)

For school health policies to be successful we need people who are highly qualified, experienced and willing to do their job, we don't want people who are not serious about their work. (P12 Male)

People should learn to take their work serious, that's the only way to achieve our aim of healthy schools. (P21) 


\section{Discussion}

This study was undertaken to explore and describe decision-makers' perspectives of the factors that influence the dissemination and implementation of a school health policy in Bayelsa state, southern Nigeria. The study revealed two themes that influence the dissemination and implementation of a school health policy, namely perceived barriers and perceived positive factors. The participants indicated that a slow bureaucratic process was a barrier to the dissemination and implementation of a school health policy. This finding is consistent with the study conducted by Gupta, Davoodi, and Tiongson $(2000,132)$ who identified government bureaucracies as a barrier to the effective implementation of school health services in India. The participants indicated that owing to the ineffective monitoring and evaluation of the dissemination and implementation of school health policy processes, there is a lack of enforcement, poor compliance and a lack of succession planning. This finding is consistent with that of Köberlein, Kothe, and Schaffert $(2011,192)$ who mentioned that effectiveness determinants to monitor and evaluate are key in the dissemination and implementation of a school health policy. Some of the participants mentioned insufficient financial support as a barrier to effective dissemination and implementation of a school health policy. The Mississippi Healthy Students Act of 2007 affirmed that successful implementation of any school health programme to better the health status of students depends largely on adequate funding (Holland et al. 2016, 314). The participants indicated that the incessant interference of politicians in the health affairs of schools has caused a significant setback in the dissemination and implementation of a school health policy in Bayelsa state, southern Nigeria.

These findings are in line with those of Chadambuka et al. $(2018,57)$ who found that the lack of opportunities is harmful to any well-meaning organisation, because it reduces the enthusiasm of stakeholders and causes the ineffectiveness of programmes. The participants identified the dysfunctional state of school health services owing to a lack of equity of service delivery as a perceived barrier to the effective dissemination and implementation of a school health policy. This finding is in line with Zimmerman, Steven, and Woolf $(2014,4)$ who found that unequal healthcare service delivery creates health disparities in terms of care, access to infrastructure and essential drugs as well as inequality in all spheres. It is, therefore, not surprising that a school health policy is poorly disseminated and implemented in Bayelsa state, southern Nigeria, owing to unequal service delivery. Poor working conditions were also highlighted as a barrier to the dissemination and implementation of a school health policy. These findings are consistent with those of Eiraldi et al. $(2015,124)$ who found that the right atmosphere or condition facilitates efforts to ensure that end users of school health programmes receive the school health policy rightly within the specified time frame and implemented effectively.

The majority of the participants highlighted the fact that a school health policy was ineffectively communicated. Austvoll-Dahlgren $(2009,193)$ indicates that there is a 
need for proper communication regarding school health policies. Owing to misinformation, the stakeholders lack knowledge and awareness of the existence of a school health policy. The stakeholders have not seen the school health policy and are unaware of the content of such policy. Brownson, Chriqui, and Stamatakis $(2009,1576)$ state that as a public health strategy and as a matter of public health importance, education and enlightenment are essential to engage all targeted stakeholders to perform a task and give credence to this quote, "what can be asserted without evidence can be dismissed without evidence." It could be inferred that the stakeholders who have not seen and have no knowledge of the school health policy, could be a barrier to its dissemination and implementation.

Perceived positive factors were identified as the second theme of the study. The accessibility of policy documents was identified as a positive factor for the dissemination and implementation of a school health policy. Considering the fact that documents constitute evidence-based facts and can be relied upon as evidence, the availability of such documents serves as a perceived positive factor. This finding is in line with that of Bostock, Ogievetsky, and Heer $(2011,2301)$ who found that the use of available documents and policies points to the foundation of the programme and can still be very relevant in the development of any new programme. It is, therefore, suggested that available documents be perceived as a positive factor towards the effective dissemination and implementation of a school health policy in Bayelsa state, southern Nigeria. The participants regarded considered collaborative partnership as a perceived positive factor that affects the dissemination and implementation of a school health policy. This view is consistent with the stance of the Ontario health promotion organisation (Wolanski 2015, 6).

Under the track guide for supporting parents and professionals, it was stated that collaborative partnership with other groups could establish the dissemination and implementation of a school health policy on the platform for persistent public and significant interchange. The participants indicated that existing school health programmes could enhance better decision-making to improve the promotion of school healthcare. Whelan et al. $(2014,347)$ opined that utilising existing school health programmes encourages continuity, thereby creating more room for policy makers and other school health promotion practitioners to be more focused in advocacy, resource mobilisation and administration to achieve positive school health outcomes. The participants indicated that the need to use competent and willing personnel in the Ministry as a perceived positive factor in furthering the course of the dissemination and implementation of a school health policy. This finding is in line with that of Johansson et al. $(2010,213)$ who found that healthcare professionals who are willing and committed, promote population healthcare. 


\section{Limitations of the Study}

A key limitation that affected this study was that the southern areas in Nigeria do not have trained school health nurses or physicians. This probably could be the reason why the dissemination and implementation of a school health policy is ineffective. This could also be one of the reasons why the lack of manpower was an issue emphasised over and over in the study. Moreover, owing to delays in obtaining ethical approval from the Faculty of Health Science Ethics Committee, time constraints affected the study, making it a little hasty. In addition, the individual interviews conducted in Ministry B, which was also a key Ministry, had only three willing participants. The poor participation of key relevant stakeholders could make the findings less empowering. The few participants could provide inaccurate findings and provide fewer opportunities for mutual knowledge creation among stakeholders, and could have promoted commitment and dedication for adopting a helpful feat to disseminate and implement a school health policy.

\section{Conclusion}

The aim of this study was to explore and describe the factors that influence the dissemination and implementation of a school health policy in Bayelsa state, southern Nigeria. The study revealed two themes, namely perceived barriers and perceived positive factors as factors that influence the dissemination and implementation of a school health policy in Bayelsa state, southern Nigeria. These findings show that for the dissemination and implementation of a school health policy to be effective, these identified factors need be dealt with through activities that would reduce government bureaucratic acts, and create knowledge and awareness, among others. However, effective monitoring systems and the enabling environment should be created. In the light of the above findings, there is a need for further research, perhaps using other methods to identify specific reasons why there are no trained school health nurses or physicians in the State to proffer solutions.

\section{Acknowledgements}

This study was funded by the North-West University. The efforts of the independent coders, Dr Annatjie van der Wath and Dr Izibeloko Jack-Ide, are highly appreciated.

\section{References}

Adebayo, A. M. and M. O. Onadeko. 2015. "Knowledge of School Health Programme among Public Primary School Teachers in Oyo State, South-Western Nigeria: A Rural-Urban Comparative Study." African Journal of Reproductive Health 19 (3): 55-60. https://doi.org/10.1007/s10389-015-0668-5. 
Austvoll-Dahlgren, A. 2009. "Bottom-Up Approach to Successful Implementation of Pharmaceutical Policy. Expert Review of Pharmacoeconomics and Outcomes Research 9 (3): 193-5. https://doi.org/10.1586/erp.09.11.

Bostock, M., V. Ogievetsky, and J. Heer. 2011. "D³ Data-Driven Documents." IEEE Transactions on Visualization and Computer Graphics 17 (12): 2301-9. https://doi.org/10.1109/TVCG.2011.185.

Bradbury, A., and G. Roberts-Holmes. 2016. "The Introduction of Reception Baseline Assessment. ATL and NUT.” Accessed 20 March 2019.

http://discovery.ucl.ac.uk/1476041/1/baseline-assessment--final-10404.pdf.

Brener, N. D., H. Wechsler, and L. Kann. 2014. "Challenges in and Strategies for the Surveillance of School Health Policies and Practices: A Commentary." Journal of School Health 84 (11): 687-94. https://doi.org/10.1111/josh.12204.

Brink, H., C. van der Walt, and G. van Rensburg. 2012. Fundamentals of Research Methodology for Health Care Professionals. 3rd ed. Cape Town: Juta.

Brownson, R. C., J. F. Chriqui, and K. A. Stamatakis. 2009. "Understanding Evidence-Based Public Health Policy.” American Journal of Public Health 99 (9): 1576-83. https://doi.org/10.2105/AJPH.2008.156224.

Chadambuka, A., L. Katirayi, A. Muchedzi, E. Tumbare, R. Musarandega, A. I. Mahomva, and G. Woelk. 2018. "Acceptability of Lifelong Treatment among HIV-Positive Pregnant and Breastfeeding Women (Option B+) in Selected Health Facilities in Zimbabwe: A Qualitative Study." BMC Public Health 18 (1): 57-59. https://doi.org/10.1186/s12889017-4611-2.

Creswell, John W., and Vicki L. Plano Clark. 2017. Designing and Conducting Mixed Methods Research. 3rd ed. Los Angeles: Sage.

Eiraldi, R., C. B. Wolk, J. Locke, and R. Beidas. 2015. "Clearing Hurdles: The Challenges of Implementation of Mental Health Evidence-Based Practices in Under-Resourced Schools. Advances in School Mental Health Promotion 8 (3): 124-40. https://doi.org/10.1080/1754730X.2015.1037848.

Gupta, S., H. Davoodi, and E. Tiongson. 2000. "Corruption and the Provision of Health Care and Education Services.” In The Political Economy of Corruption, 123-53. Routledge.

Hildebrand, D. A., N. M. Betts, and G. E. Gates. 2019. "Parents' Perceptions of Childhood Obesity and Support of the School Wellness Policy." Journal of Nutrition Education and Behavior 51 (4): 498-504. https://doi.org/10.1016/j.jneb.2018.12.009.

Holland, J. H., J. J. Green, L. Alexander, and M. Phillips. 2016. "School Health Policies: Evidenced-Based Programs for Policy Implementation." Journal of Policy Practice 15 (4): 314-32. https://doi.org/10.1080/15588742.2015.1081580. 
Johansson, H., H. Stenlund, L. Lundström, and L. Weinehall. 2010. "Reorientation to more Health Promotion in Health Services-A Study of Barriers and Possibilities from the Perspective of Health Professionals." Journal of Multidisciplinary Healthcare 3:213-20. https://doi.org/10.2147/JMDH.S14900.

Köberlein, J., A. C. Kothe, and C. Schaffert. 2011. "Determinants of Patient Compliance in Allergic Rhino Conjunctivitis." Current Opinion in Allergy and Clinical Immunology 11 (3): 192-9. https://doi.org/10.1097/ACI.0b013e3283466fcb.

Koegel, L. K., R. L. Koegel, K. Ashbaugh, and J. Bradshaw. 2014. "The Importance of Early Identification and Intervention for Children with or at Risk for Autism Spectrum Disorders.” International Journal of Speech-Language Pathology 16 (1): 50-56. https://doi.org/10.3109/17549507.2013.861511.

Macnab, A. J., F. A. Gagnon, and D. Stewart. 2014. "Health Promoting Schools: Consensus, Strategies, and Potential." Health Education 114 (3): 170-85. https://doi.org/10.1108/HE11-2013-0055.

Mohlabi, D. R., E. J. van Aswegen, and J. D. Mokoena. 2010. "Barriers to the Successful Implementation of School Health Services in the Mpumalanga and Gauteng Provinces." South African Family Practice 52 (3): 249-54. https://doi.org/10.1080/20786204.2010.10873983.

National Departments of Health and Basic Education. 2012. Integrated School Health Policy. https://serve.mg.co.za/content/documents/2017/06/14/integratedschoolhealthpolicydbeand doh.pdf.

Obembe, T. A., K. O. Osungbade, and O. M. Ademokun. 2016. "Awareness and Knowledge of National School Health Policy and School Health Programme among Public Secondary School Teachers in Ibadan Metropolis." Nigerian Medical Journal: Journal of the Nigeria Medical Association 57 (4): 217-35. https://doi.org/10.4103/0300-1652.188341.

Ofovwe, G. E., and A. N. Ofili. 2010. "Prevalence and Impact of Headache and Migraine among Secondary School Students in Nigeria." Headache: The Journal of Head and Face Pain 50 (10): 1570-5.

Rasesemola, R. M., G. P. Matshoge, and T. S. Ramukumba. 2019. "Compliance to the Integrated School Health Policy: Intersectoral and Multisectoral Collaboration." Curationis 42 (1): 1-8. https://doi.org/10.4102/curationis.v42i1.1912.

Saito, J., N. Keosada, S. Tomokawa, T. Akiyama, S. Kaewviset, D. Nonaka, J. Waikugul, J. Kobayashi, M. Souvanvixay, and M. Jimba. 2014. "Factors Influencing the National School Health Policy Implementation in Lao PDR: A Multi-Level Case Study." Health Promotion International 30 (4): 843-54. https://doi.org/10.1093/heapro/dau016. 
Whelan, J., P. Love, T. Pettman, J. Doyle, S. Booth, E. Smith, and E. Waters. 2014. "Cochrane Update: Predicting Sustainability of Intervention Effects in Public Health Evidence: Identifying Key Elements to Provide Guidance.” Journal of Public Health 36 (2): 347-51. https://doi.org/10.1093/pubmed/fdu027.

WHO (World Health Organization). 2017." School and Youth Health: Global School Health Initiative.” Accessed 12 July 2017. https://www.who.int/school_youth_health/gshi/en/.

Wolanski, A. 2015. "Factors Affecting Child Development." Accessed 10 April 2019. https://www.beststart.org/OnTrack_English/2-factors.html.

Zimmerman, E. B., H. Steven, Woolf, and A. Haley. 2015. "Understanding the Relationship between Education and Health: A Review of the Evidence and an Examination of Community Perspectives." Population Health: Behavioral and Social Science Insights. AHRQ Publication 15 (1): 347-84. 